\title{
Optimization of Hotel Financial Management Information System Based on Computational Intelligence
}

\author{
Hongmei Ma $(\mathbb{D}$ \\ School of Business Administration, Tourism College of Zhejiang, Hangzhou 311231, China \\ Correspondence should be addressed to Hongmei Ma; mhm@tourzj.edu.cn
}

Received 30 August 2021; Revised 30 October 2021; Accepted 1 November 2021; Published 30 November 2021

Academic Editor: Deepak Gupta

Copyright (c) 2021 Hongmei Ma. This is an open access article distributed under the Creative Commons Attribution License, which permits unrestricted use, distribution, and reproduction in any medium, provided the original work is properly cited.

\begin{abstract}
Nowadays, the hotel management concept cannot keep pace with the times. Traditional concepts are often adopted to manage hotel financial personnel, for the hotel financial personnel cannot take timely and effective training. All these lead to the hotel financial staff designing the hotel's related business without sufficient understanding of the hotel industry and judging and deciding if they do not master the hotel's professional knowledge, which makes the participating projects unable to give correct and reasonable answers to the substantive problems of the hotel. This leads to the hotel management not going up; extensive management makes the hotel benefit not go up. Hotel intelligent technology can solve these problems and not only save manpower and material resources but also intelligently predict the financial crisis of hotels. In the context of the accelerated development of globalization and informatization, there are still many problems in the financial management process of my country's hotel industry. Based on these questions, the article draws on foreign advanced experience, puts forward effective suggestions in financial management, and uses computational intelligence technology to design a centralized and intelligent financial management system. The research results show the following: (1) the financial crisis model is created by using the principle of support vector machine and logistic regression method, which greatly reduces the financial crisis of the enterprise. (2) The system can straightforwardly summarize the data for easy query. Taking three domestic hotels as an example, a comprehensive study has been carried out on the three aspects of pricing assessment risk, financial integration risk, and debt risk. In 2016, the financial leverage coefficient has been relatively high, the quick ratio has fluctuated greatly, and the interest protection coefficient has shown a downward trend. (3) The performance of the system is compared with traditional development mode, framework development mode, and intelligent optimization mode. The intelligent optimization system has the lowest response time and the highest success rate. The new system has reduced response time by about $57 \%$ compared with the original response time, and the access success rate has been greatly improved.
\end{abstract}

\section{Introduction}

The arrival of the information age has given new meaning to hotels. Traditional hotel financial management models can no longer meet today's needs, so it is inevitable to apply intelligence to hotel financial management. Literature [1] pointed out the problems existing in the financial management process of the hotel industry in our country. According to these problems, we need to reform and innovate the existing financial management system and continuously optimize the hotel's financial management system. Literature [2] explains the basic principles of financial management in the hotel industry. Literature [3] proposed an intelligent financial management system. This system is a system designed based on Python. It has many potential benefits. It can help the hotel better control costs, improve the hotel's core competitiveness, and lay the foundation for the hotel's long-term development. At present, most hotels have applied information management to all parts of the hotel, especially in terms of financial management. Whether the hotel has a complete financial management system is directly related to the longterm development of the hotel. Literature [4] proposed a fuzzy-based analytic hierarchy process (FAHP) to consider user perception to access decision-making. Use computing intelligence to extract hotel information, establish customer models, realize the hotel's "customer-centric" concept, 
improve the hotel's core competitiveness, and lay a solid foundation for the hotel's long-term development. Literature [5] develops a powerful and reliable model for evaluating the quality of hotel websites. The resulting model can evaluate the hotel's website in an all-round way, which is a very important task for enterprises. Literature [6] tested the application of smart technology in the hotel industry. We conducted a survey of many top hotels in five surrounding cities in China and found that the intelligence of hotels can be divided into three levels. Literature [7] developed a wireless ordering system based on Android phones for the needs of high-end hotel brand marketing services. Literature [8] used sustainable growth models and applied profit and risk graphs based on DuPont equations to investigate whether there is a connection between hotel financial management and management decision-making. We conducted a data analysis on two domestic hotels and calculated the profit of the hotel. The results of the study showed that the management of the manager has a great relationship with the financial situation of the hotel. The article pointed out the methods that the hotel can increase profitability. Literature [9] investigates the core financial analysis capabilities that hotel managers must possess. The literature [10] pointed out that recent reports focusing on the future of the global hotel industry have determined that key management issues include the impact of new technologies, lack of capital investment, and increasing attention to the future of the environment. The role of hotel finance director is very important for hotels. In recent years, people's perception of the role of hotel finance director has also changed tremendously. This position is also involved in the hotel's management team. The status in people's hearts has gradually increased. Literature [11] introduces some results of a research project, investigating the role of financial controller in the 10 years up to 1990. Literature [12] introduced the compilation method and indicator analysis of the cash flow statement. Literature [13] examines the combined impact of management response and online comments on hotel financial performance. We have collected a lot of data in the management responses to the online reviews of many online consumers. The research found that a high response rate can improve the financial performance of the hotel, while nonreplying will have a slight impact on the performance of the hotel, so more information should be provided. Reply more to improve the performance of the hotel. Literature [14] investigates the relationship between comprehensive quality management elements and customer attention and financial performance. Literature [15] investigates the relationship between the acquisition amount, the number of acquisition target hotels, and the financial performance of the hotel group after the acquisition. The research results show that the size of the acquisition has a significant impact on the financial performance of the acquirer's hotel, and the degree of impact varies according to different indicators of the company's financial performance. As an important part of hotel operation management, financial management not only involves hotel internal management, cost control, and payment but also affects hotel operation decision. Compared with large hotels, the management of small and medium-sized hotels has cer- tain limitations, poor antirisk ability, and weak financial management awareness of managers, which easily constrains the development of hotels. Science and technology drive the development of human life in the future. Intelligent hotels can meet customer needs in all directions and realize the concept of hotel service first and customer first. In today's society with expensive human and material resources, intelligent technology has become the future trend of hotel development. Pujie Technology uses artificial intelligence to bring new vitality and new development to the hotel industry and meets the unique experience needs of customers with the principle of customer first.

\section{Research Background}

2.1. Research Significance. Different from hotels in the economically backward era, their main function is to provide customers with catering and accommodation services. On this basis, today's hotels are more comprehensively developed into very comprehensive social service organizations. The services provided by hotels are also increasing. Hotels have gradually become an indispensable part of people's lives. Hotels have driven my country's economic development and become my country's third emerging industry, which is closely related to the development of tourism. On the other hand, in large and medium-sized cities, hotel business is a common place for business negotiations and fitness sessions, and the demand for high-quality services is very necessary. The financial management of the hotel means that the financial staff is responsible for the statistics, summary, comprehensive analysis of the results, and conclusions of the various currency and capital exchanges and values collected by various financial institutions or units in the hotel's operating activities, and it is the hotel's general managers who provide information closely related to the management business in order to make correct business decisions. The popularization and development of information technology have opened up a new idea for the financial management of my country's tourism catering service industry. If this information technology is widely used in the financial management of tourism catering companies, it can provide tourism catering companies with more intelligent and automated financial management, including some daily financial and peacetime accounting management; if you make full use of the computer to manage it, on the one hand, you can effectively avoid financial management omissions; on the other hand, it is also for the convenience of inspection. The use of information technology to manage hotel financial data can share and manage the financial data of branches in multiple locations in real time under the premise of ensuring safety, which is very critical and important for hotel group management.

2.2. The Necessity of Hotel Financial Management. In the development of China's hotel industry for decades, although it is concentrated in the two aspects of catering and accommodation, the hotel has undergone revolutionary innovation and transformation in many aspects [16]. Any department and hotel operation management are any part of this 
process, including project management, accounting, capital management, fixed asset management, material and supply management, office supplies and equipment for various functional departments, hotel procurement and leasing contract management, and management of large warehouses, from the purchase of raw materials to processing and later sales of the hotel; any department and hotel management are any part of this process, including project management, accounting, capital management, and fixed asset management. In supply management of materials and supplies, office supplies and equipment of various functional departments, hotel procurement and lease contract management, and large warehouse procurement management, from the purchase of raw materials to processing and later sales of the hotel, all the details are required because we need financial management, mainly manifested in the following aspects: the financial management of the hotel is related to the development of the hotel. The hotel's financial management is directly related to whether a hotel company can truly obtain long-term operations. Each department of the hotel also has traces of financial management. Any activity or action in the hotel is also inseparable from hotel finance. With the help and support of management, at the same time, by predicting the cost and benefit of various business activities, the hotel can clearly understand and master its own overall financial situation.

(a) The financial management of the hotel is related to the development of the hotel. The hotel's financial management is directly related to whether a hotel company can truly obtain long-term operations. Each department of the hotel also has a trace of financial management. Any activity or some action in the hotel is also inseparable from hotel finance. With the help and support of management, at the same time, by predicting the cost and benefit of various business activities, the hotel can clearly understand and master its own overall financial situation

(b) Financial management can reflect hotel operations, and hotel revenue, costs, and fluctuations can be reflected in the hotel's financial management activities [17]. The hotel management staff should formulate the company's development strategy according to the hotel's operating conditions to achieve the long-term development of the hotel

(c) Conducive to hotel cost control. The hotel's financial system can effectively control the various activities carried out by the hotel and ensure the rational use of hotel funds and the regeneration of funds [18]

2.3. Analysis of the Status Quo of Hotel Financial Management. The traditional corporate finance department is mainly responsible for recording and managing the various expenditures of the enterprise, while the corporate finance department of the new era has more functions, including observation of the market where the enterprise is located and the management of the enterprise based on the existing financial information. Provide strategic advice on future development. The settings include in-depth exploration of financial data and discovering some invisible corporate conditions on the surface. Many corporate financial management systems have been developed abroad. These corporate financial management systems include improvements to accounting and provide good support for voucher management and bank reconciliation. Some systems can even be connected with other companies in the production chain in the industry, such as Oracle's Financial Analyzer system, which can provide a very friendly management function for traditional corporate finance. The hotel's financial management department has a weak sense of supervision, and many problems have arisen in the hotel's operation process because the hotel's related systems are not perfect and cannot regulate and restrict employees.

\subsection{Countermeasures and Suggestions for Hotel Financial} Management. For some modern commercial hotel companies, financial management was an important management content at the time, and it was also regarded as an effective guarantee for the hotel companies' competitiveness in the international market. When our hotel companies want to further improve their own operating efficiency, they need to further enhance their own awareness of financial management significance and importance, and continue to strengthen the supervisory function of financial management workers and the sense of responsibility of employees, so that all employees of our hotel can fully realize the importance of financial management. It is clarified that the financial management work is closely related to the corporate procurement department and its market administrative department, further strengthens the management concept of the corporate financial department, builds a stricter operation and management system, further optimizes the business process of the hotel company, and implements financial supervision, to ensure that the operation and management of hotel companies have more extensive supervision powers and to promote communication and cooperation between other operation and management departments and the financial departments of hotel companies, so as to ensure that the hotel operation and management system and financial management work can be carried out in a regular manner. Moreover, financial management work will also be implemented, helping hotel business management and development work to play a practical effect.

2.5. Hotel Financial Management System Design. The financial part should judge the feasibility of decision-making based on conditions such as market and cost control and maximize the profit of the hotel as much as possible [19]. The financial management department divides positions according to parts and performs their duties. The financial department sets up cashier positions to control the turnover of funds. The issue of reserve funds should be managed by the procurement department. Under the conditions of analyzing the production needs of the hotel, the funds should be reasonably controlled to promote the turnover rate of funds. Set up a tax planning system. Form an asset flow management system to reduce waste of inventory and increase capital turnover [20]. 


\subsection{Financial Model Construction}

2.6.1. Optimized Quantitative Model of Business Model. Assuming $p$ variable $X_{1}, X_{2}, \cdots, X_{P}$, each variable has $n$ pairs of measured values, and assuming that the measured values of $X_{1}, X_{2}, \cdots, X_{P}$, vary independently, the statistical distance from any point $P=\left(X_{1}, X_{2}, \cdots, X_{P},\right)$ to any fixed point $Q=\left(y_{1}, y_{2}, \cdots, y_{P},\right)$ is [21]

$$
d(p, Q)=\sqrt{\frac{\left(x_{1}-y_{1}\right)^{2}}{S_{11}}+\frac{\left(x_{2}-y_{2}\right)^{2}}{S_{22}}+\frac{\left(x_{p}-y_{p}\right)^{2}}{S_{p p}}} .
$$

If $S_{k}$ is the sample standard deviation, then

$$
S_{k}^{2}=S_{k k}=\frac{1}{n} \sum_{j=1}^{k}\left(x_{j k}-\bar{x}_{k}\right)^{2}, \quad k=1,2, \cdots, p .
$$

$\bar{X}_{k}$ is the mean value of the $k$ th variable; there are

$$
\bar{X}_{k}=\frac{1}{n} \sum_{j=1}^{k} X_{j k}
$$

When the coordinate values are not independent, the original coordinate system needs to be rotated by the angle $\theta$, and the statistical distance from any point $P=\left(X_{1}, X_{2}\right.$, $\left.\cdots, X_{P}\right)$ to any fixed point $Q=\left(y_{1}, y_{2}, \cdots, y_{P}\right)$ is [22]

$$
d(p, Q)=\left[a_{11}\left(x_{1}-y_{1}\right)^{2}+2 a_{12}\left(x_{1}-y_{1}\right)\left(x_{2}-y_{2}\right)+\cdots\right]^{1 / 2}
$$

Solve

$$
\begin{aligned}
d^{2}(p, Q) & =d(p, Q) \\
& =\left[a_{11}\left(x_{1}-y_{1}\right)^{2}+2 a_{12}\left(x_{1}-y_{1}\right)\left(x_{2}-y_{2}\right)+\cdots\right] \\
& =(X-Y) T A(X-Y),
\end{aligned}
$$

where

$$
\begin{gathered}
A=\left(a_{i j}\right), \quad i, j=1,2, \cdots 5 \\
(X-Y)^{T}=\left[x_{1}-y_{1}, x_{2}-y_{2} \cdots x_{5}-y_{5}\right] .
\end{gathered}
$$

Find the first derivative of formula (5), and the other is 0 ; there are

$$
\frac{\partial[(X-Y) T A(X-Y)]}{\partial(X-Y)}=2 A(X-Y)=0 .
$$

Any point $p$ on the objective function satisfies

$$
y=x_{1} \times x_{2} \times x_{3} \times x_{4} \times x_{5} .
$$

2.6.2. Construction of Financial Crisis Early Warning Model. Support vector machine [23] is applied to two clas- sifications, and the specific classification is shown in Figure 1.

We set the dividing line of the support vector machine to $g(x)$ :

$$
g(x)=\left(a_{1} x+b_{1}\right)=0
$$

Among them, $\{y \mid(-1 \leq y \leq 1)\} x \in R_{1}$ is $g(x)>0, y=1$. When $x \in R_{2}, g(x)<0, y=-1$. The function can be expressed as

$$
\begin{aligned}
& \left(a_{1} x\right)+b_{1}=-k \\
& \left(a_{1} x\right)+b_{1}=k .
\end{aligned}
$$

To transform the above formula, there are

$$
\left\{\begin{array}{l}
g(x)=\left(a_{1} x+b_{1}\right)=0 \\
\left(a_{1} x\right)+b_{1}=-1 \\
\left(a_{1} x\right)+b_{1}=1
\end{array}\right.
$$

And because

$$
\|a\|=\frac{\|a\| I}{k}
$$

find the minimum value of $\|a\|$ and turn the problem into a constrained optimization problem:

$$
\text { s.t. } y i\left\{\left(a_{1} x\right)+b_{1}\right\} \geq 1 \text {. }
$$

Introduce the Lagrangian multiplier

$$
L(a, \alpha)=\frac{1}{2}\|a\|^{2}-\sum_{i}^{n} \alpha_{i} y_{i}(a x+b)+\sum_{i}^{n} \alpha_{i} .
$$

Finally,

$$
y(x)=\operatorname{sgn} \sum_{i=1}^{n} \alpha_{i} y_{i} x_{i}^{T} x+b .
$$

Assuming there is $a$ sample, for each sample $b$ description indicators, we can use a matrix to represent the sample:

$$
x=\left(\begin{array}{ccc}
x_{11} & \cdots & x_{1 b} \\
\vdots & \ddots & \vdots \\
x_{a 1} & \cdots & x_{a b}
\end{array}\right)
$$

The data standardization processing formula is

$$
x=\frac{x_{a b}-\bar{x}_{b}}{\sqrt{\operatorname{Var}\left(x_{a}\right)}}, \quad a \in(1, n), b \in(1, p) .
$$




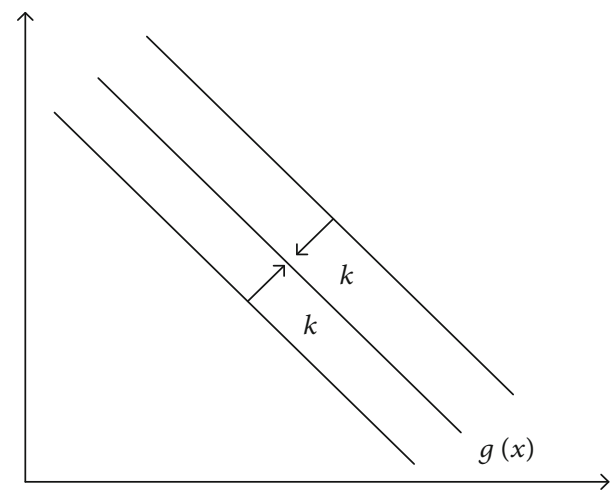

Figure 1: Schematic diagram of support vector machine.

Calculate the covariance:

$$
\Sigma=\left\{\begin{array}{l}
\operatorname{Var}\left(x_{1}\right) \operatorname{Cov}\left(x_{1}, x_{2}\right) \cdots \operatorname{Cov}\left(x_{1}, x_{p}\right) \\
\operatorname{Cov}\left(x_{2}, x_{1}\right) \operatorname{Var}\left(x_{2}\right) \cdots \operatorname{Cov}\left(x_{2}, x_{p}\right) \\
\vdots \\
\operatorname{Cov}\left(x_{n}, x_{1}\right) \operatorname{Cov}\left(x_{n}, x_{2}\right) \cdots \operatorname{Var}\left(x_{p}\right)
\end{array}\right.
$$

Introduce the eigenvalues and eigenvectors of the matrix:

$$
\begin{aligned}
& e=\left(e_{1}, e_{2}, e_{3} \cdots e_{p}\right), \\
& \lambda=\operatorname{diag}\left(\lambda_{1}, \lambda_{2}, \lambda_{3} \cdots \lambda_{p}\right) .
\end{aligned}
$$

The main component results obtained are

$$
\left\{\begin{array}{l}
F_{1}=e_{11} x_{1}+e_{21} x_{2}+e_{31} x_{3}+\cdots e_{p 1} x_{p} \\
F_{2}=e_{12} x_{1}+e_{22} x_{2}+e_{32} x_{3}+\cdots e_{p 2} x_{p} \\
\vdots \\
F_{p}=e_{1 p} x_{1}+e_{2 p} x_{2}+e_{3 p} x_{3}+\cdots e_{p p} x_{p}
\end{array}\right.
$$

The linear model is used for fitting, and the following formula is obtained according to the principle:

$$
P_{i}=f\left(\beta_{0}+\beta_{1} X_{i 1}+\beta_{2} X_{i 2}+\cdots \beta_{n} X_{\text {in }}\right) \text {, }
$$

where

$$
f=\frac{e x}{1+e x}
$$

Express $Y_{i}$ in another way:

$$
P\left(Y_{i}\right)=\pi_{i} y_{i}(1-\pi) 1-y_{i}
$$

The logarithms obtained by using the method of maximum similarity function are

$$
\begin{aligned}
\operatorname{LnL} & =\sum_{i=1}^{n} y_{i} \ln \pi_{i}+\left(1-y_{i}\right) \ln \left(1-\pi_{i}\right), \\
\pi_{i} & =\exp \left(\beta_{0}+\beta_{1} X_{i 1}+\cdots \beta_{n} X_{\text {in }}\right) A+\exp \left(\beta_{0}+\beta_{1} X_{i 1}+\cdots \beta_{n} X_{\text {in }}\right) .
\end{aligned}
$$

TABLE 1: Comparison table of property rights' rate of 3 top hotels in China.

\begin{tabular}{lcccc}
\hline Project & 2016 & 2015 & 2014 & 2013 \\
\hline Hotel one & $116.01 \%$ & $165.78 \%$ & $64.18 \%$ & $66.69 \%$ \\
Hotel two & $188.58 \%$ & $192.22 \%$ & $23.313 \%$ & $54.18 \%$ \\
Hotel three & $85.08 \%$ & $124.29 \%$ & $92.20 \%$ & $84.14 \%$ \\
Average value & $129.89 \%$ & $162.10 \%$ & $59.56 \%$ & $68.34 \%$ \\
\hline
\end{tabular}

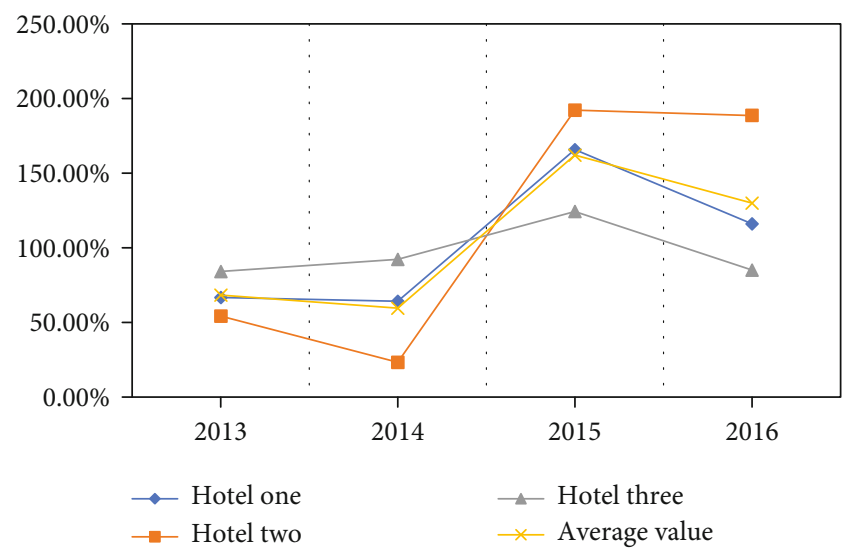

Figure 2: Change in equity ratio.

TABLE 2: Financial leverage coefficient comparison.

\begin{tabular}{lcccc}
\hline Project & 2016 & 2015 & 2014 & 2013 \\
\hline Hotel one & 1.58 & 1.75 & 1.17 & 1.18 \\
Hotel two & 1.69 & 1.40 & 1.10 & 1.08 \\
Hotel three & 1.08 & 1.05 & 1.07 & 1.02 \\
Average value & 1.45 & 1.40 & 1.11 & 1.09 \\
\hline
\end{tabular}

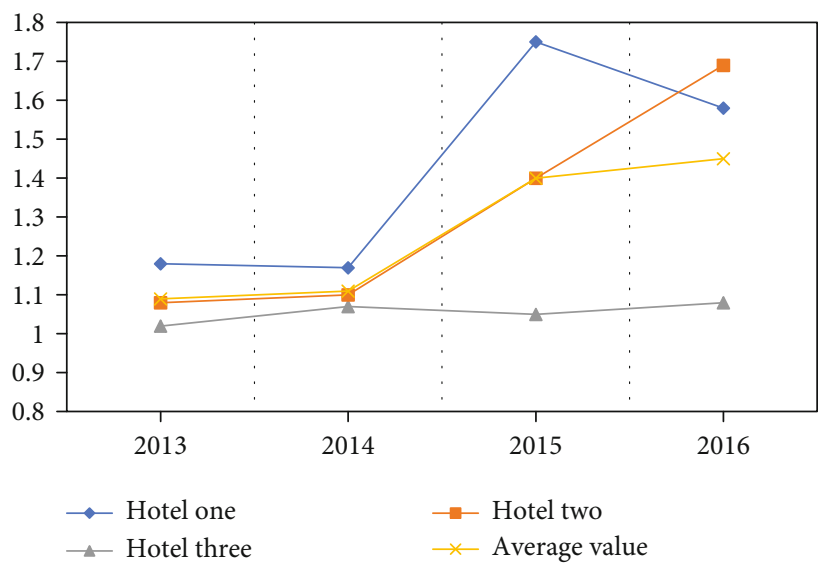

Figure 3: Changes in financial leverage coefficient. 
TABLE 3: Quick ratio comparison table.

\begin{tabular}{lcccc}
\hline Project & 2016 & 2015 & 2014 & 2013 \\
\hline Hotel one & 0.23 & 0.21 & 0.93 & 0.92 \\
Hotel two & 0.80 & 0.77 & 1.93 & 0.36 \\
Hotel three & 1.18 & 0.67 & 0.55 & 0.34 \\
Average value & 0.74 & 0.55 & 1.14 & 0.54 \\
\hline
\end{tabular}

The following equation is obtained:

$$
\begin{aligned}
\operatorname{LnL}= & \sum_{i=1}^{n} y_{i}\left(\beta_{0}+\beta_{1} X_{i l}+\cdots \beta_{n} X_{\text {in }}\right) \\
& -\ln \left[1+\exp \left(\beta_{0}+\beta_{1} X_{i l}+\cdots \beta_{n} X_{\text {in }}\right)\right] .
\end{aligned}
$$

The linear regression model is used to find the linear relationship coefficient $\beta$ between dependent variable $Y$ and independent variable $X$, which satisfies $Y=X \beta$. At this time, the dependent variable $Y$ is required to be continuous, so it is a regression model. If the dependent variable $Y$ is discrete, we need to do another function transformation for this $Y$ to become $G(Y)$. If the value of $G(Y)$ is Class A when it is in a real number interval, Class $B$ when it is in another real number interval, and so on, we get a classification model. In credit risk control, the value of default probability is changeable. By constructing dummy variable $Y$ and setting critical value, the value of default probability is transformed into two variables. When the default probability is greater than the critical value, the value is 1 ; that is, the customer will default; when the default probability is less than the critical value, the value is 0 ; that is, the customer will not default. Assuming that the probability of dependent variable $y=1$ is $p$ under the given condition of independent variable $x$, which is denoted as $p=P(y=1 \mid x)$, then the probability of $y=0$ is $1-p$, the probability ratio $p /(1-p)$ of dependent variable taking 1 and 0 is called dominance ratio, and the natural logarithm of dominance ratio is taken; then, sigmoid function can be obtained.

This paper puts forward two methods; one is the business model optimization quantification model; the other is the financial crisis early warning model; the financial crisis early warning model is obtained by the principle of support vector machine and principal component analysis.

\section{Simulation Experiment}

3.1. Experimental Environment and Data Sources. The article selects 4 top hotels in China, analyzes the hotel's financial operating conditions over the past 4 years, and calculates the hotel's property rights ratio, as shown in Table 1 and Figure 2.

3.2. Simulation Experiment. The analysis of financial leverage coefficient is shown in Table 2 and Figure 3.

From Figure 3, we can see that from 2013 to 2015, the financial leverage of hotel one has been higher than that of the other two hotels. This shows that the financial risk of hotel one is greater than that of the other two hotels, and the hotel should take relevant measures to reduce it (financial risk).

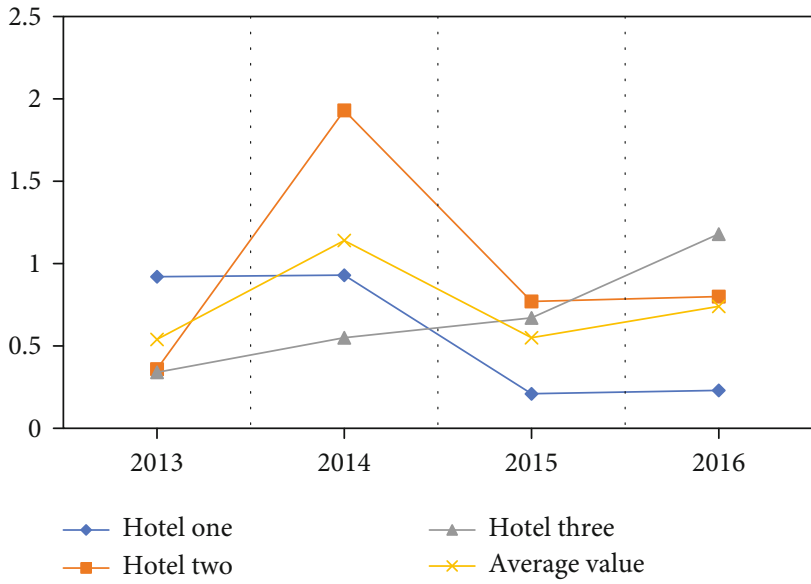

Figure 4: Hotel quick ratio change graph.

TABLE 4: Comparison of cash flow ratio.

\begin{tabular}{lcccc}
\hline Project & 2016 & 2015 & 2014 & 2013 \\
\hline Hotel one & 0.19 & 0.21 & 0.93 & 0.92 \\
Hotel two & 0.19 & 0.77 & 1.93 & 0.36 \\
Hotel three & 1.18 & 0.67 & 0.55 & 0.34 \\
Average value & 0.74 & 0.55 & 1.14 & 0.54 \\
\hline
\end{tabular}

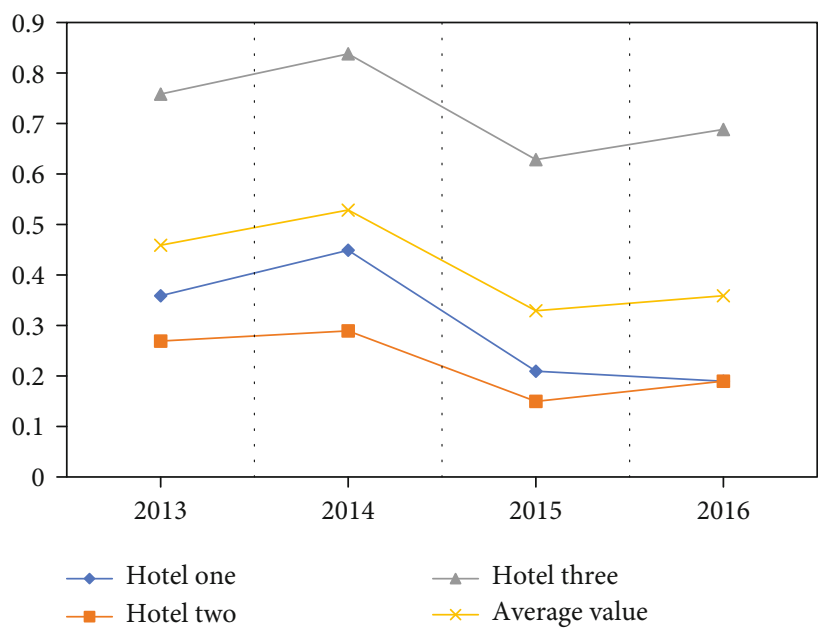

Figure 5: Cash flow ratio chart.

TABLE 5: Comparison table of interest coverage multiples.

\begin{tabular}{lcccc}
\hline Project & 2016 & 2015 & 2014 & 2013 \\
\hline Hotel one & 2.72 & 2.34 & 6.93 & 6.69 \\
Hotel two & 2.44 & 3.49 & 11.02 & 13.67 \\
Hotel three & 13.20 & 19.97 & 16.15 & 49.37 \\
Average value & 6.12 & 8.60 & 11.73 & 23.24 \\
\hline
\end{tabular}




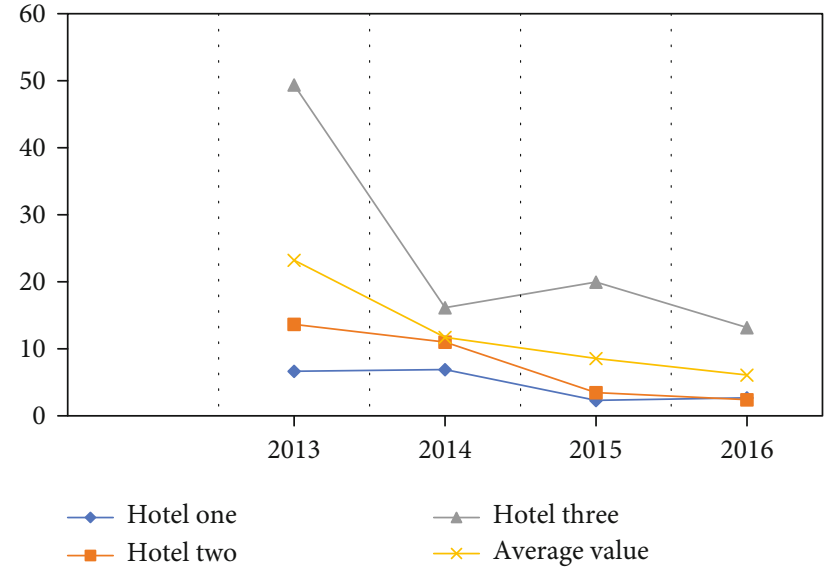

FIGURE 6: Changes in interest coverage multiples.

\subsection{Debt Repayment Risk Identification}

\subsubsection{Analysis of Short-Term Solvency}

(a) Analysis of quick ratio index

Adding that the quick ratio is significantly reduced at a certain moment, it proves that the short-term payment ability of the company may be insufficient, and the company may face a greater debt repayment risk [24]. The specific values are shown in Table 3 and Figure 4.

(b) Cash flow ratio analysis

Cash flow represents the liquidity of corporate assets. The higher the cash ratio, the stronger the corporate asset liquidity [25]. The specific values are shown in Table 4 and Figure 5.

According to Figure 5, we can conclude that the change trend of hotel 1's cash flow ratio is roughly the same as that of quick ratio. There was an upward trend in 2013-2014 and a downward trend in 2015-2016. Compared with the other two hotels, the cash ratio has changed significantly.

\subsubsection{Analysis of Long-Term Solvency}

(a) Analysis of interest guarantee multiple index

The value of the interest protection multiple represents the risk of the company's debt repayment, and the value of the value represents the level of the company's debt repayment risk. The specific values are shown in Table 5 and Figure 6.

We can see from Figure 6 that in the three years from 2013 to 2016, the interest coverage multiples of the three hotels have shown a downward trend as a whole, which indirectly proves the increasingly fierce competition among hotel mayors.

(b) Asset-liability ratio index analysis

The higher the asset-liability ratio index, the greater the proportion of the company's borrowed funds in the total funds. The specific data is shown in Table 6 and Figure 7.
TABLE 6: Asset-liability ratio comparison table.

\begin{tabular}{lllll}
\hline Project & 2016 & 2015 & 2014 & 2013 \\
\hline Hotel one & 59.50 & 64.50 & 39.74 & 40.44 \\
Hotel two & 67.60 & 68.64 & 23.19 & 38.15 \\
Hotel three & 45.80 & 55.28 & 47.94 & 45.69 \\
Average value & 57.63 & 62.81 & 36.96 & 41.43 \\
\hline
\end{tabular}

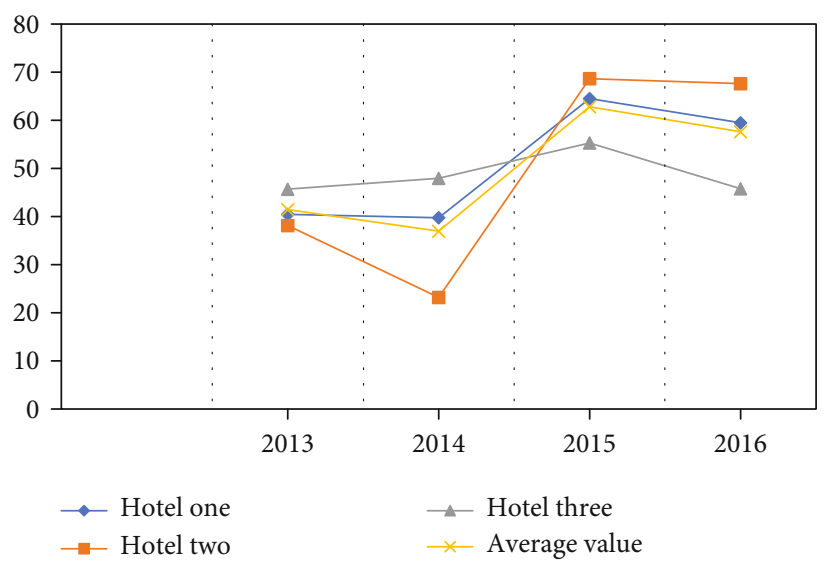

FIGURE 7: Change in asset-liability ratio.

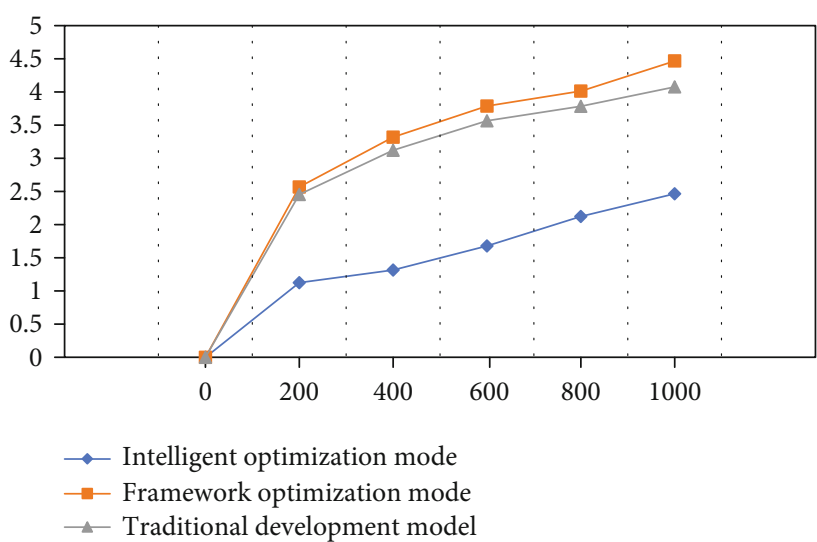

FIGURE 8: Response time vs. number of user drawing table.

Financial risk refers to the additional risks that enterprises bear by sovereign capital under the uncertain future income due to the use of debt funds. If the business is in good condition and if the enterprise's investment return rate is greater than the debt interest rate, it will get the positive effect of financial leverage. If the enterprise's operating condition is poor, making the enterprise's investment return rate less than the debt interest rate, it will get the negative effect of financial leverage and even lead to the bankruptcy of the enterprise. This uncertainty is the financial risk that the enterprise bears by using debt. The size of enterprise financial risk mainly depends on the level of financial leverage coefficient. Under normal circumstances, the greater the financial leverage coefficient, the greater the elasticity of 
TABLE 7: System query test results.

\begin{tabular}{|c|c|c|c|c|c|c|c|c|}
\hline System & Number of requests & 2000 & 2500 & 3000 & 3500 & 4000 & 4500 & 5000 \\
\hline \multirow{2}{*}{ Intelligent optimization mode } & Average response time (MS) & 33 & 45 & 55 & 95 & 135 & 205 & 279 \\
\hline & Success rate (\%) & 100 & 100 & 100 & 100 & 100 & 100 & 100 \\
\hline \multirow{2}{*}{ Framework optimization mode } & Average response time (MS) & 35 & 45 & 76 & 130 & 190 & 380 & 400 \\
\hline & Success rate (\%) & 100 & 99.7 & 99.6 & 99.5 & 99.4 & 98.4 & 99.3 \\
\hline \multirow{2}{*}{ Traditional development model } & Average response time (MS) & 42 & 55 & 90 & 200 & 380 & 350 & 500 \\
\hline & Success rate $(\%)$ & 100 & 99.4 & 99.3 & 99.2 & 99.2 & 99.1 & 99 \\
\hline
\end{tabular}

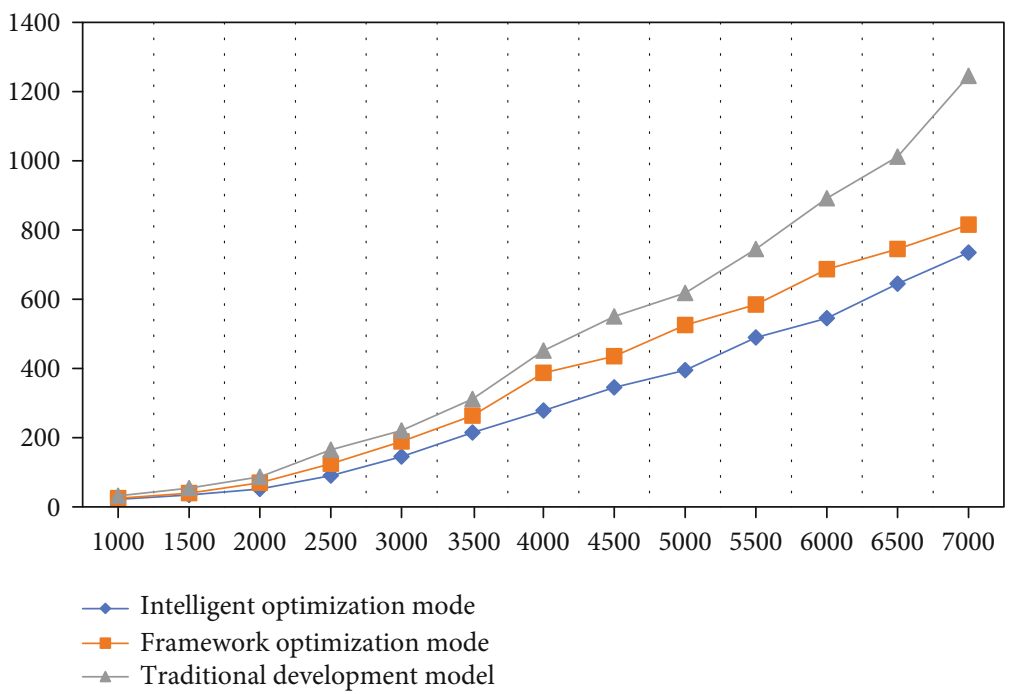

Figure 9: Request curve.

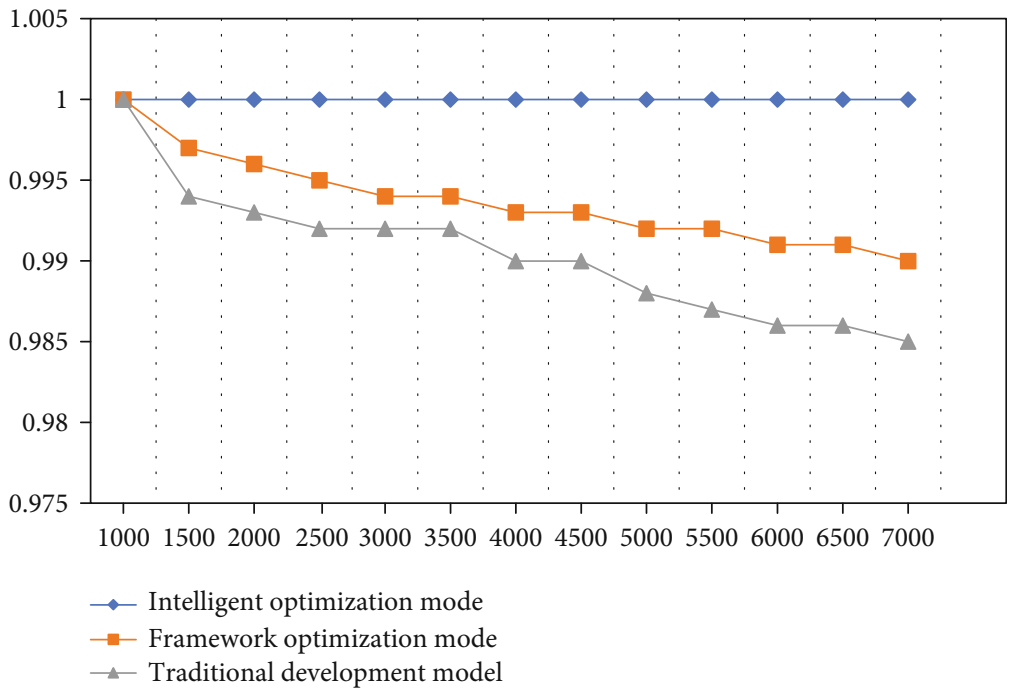

FIGURE 10: Success rate curve.

sovereign capital return rate to EBIT. If EBIT rate rises, the sovereign capital return rate will rise at a faster speed. If EBIT falls, then sovereign capital margins fall at a faster rate, and therefore, the risk is greater. On the con- trary, the financial risk is smaller. The essence of the existence of financial risks is that the part of operating risks borne by liabilities is passed on to equity capital because of debt management. 
TABLE 8: Business transaction processing function test.

\begin{tabular}{|c|c|c|c|c|c|c|c|c|}
\hline System & Number of requests & 60 & 90 & 120 & 150 & 180 & 210 & 240 \\
\hline \multirow{2}{*}{ Intelligent optimization mode } & Average response time (MS) & 75 & 190 & 250 & 350 & 500 & 700 & 820 \\
\hline & Success rate $(\%)$ & 100 & 100 & 100 & 100 & 100 & 100 & 100 \\
\hline \multirow{2}{*}{ Framework optimization mode } & Average response time (MS) & 95 & 200 & 330 & 450 & 650 & 1050 & 1400 \\
\hline & Success rate $(\%)$ & 100 & 99.5 & 99.4 & 99.4 & 99.3 & 99.2 & 99.1 \\
\hline \multirow{2}{*}{ Traditional development model } & Average response time (MS) & 150 & 250 & 400 & 500 & 800 & 1300 & 160 \\
\hline & Success rate $(\%)$ & 99.6 & 99.4 & 99.3 & 99.2 & 99.1 & 89.9 & 89.7 \\
\hline
\end{tabular}

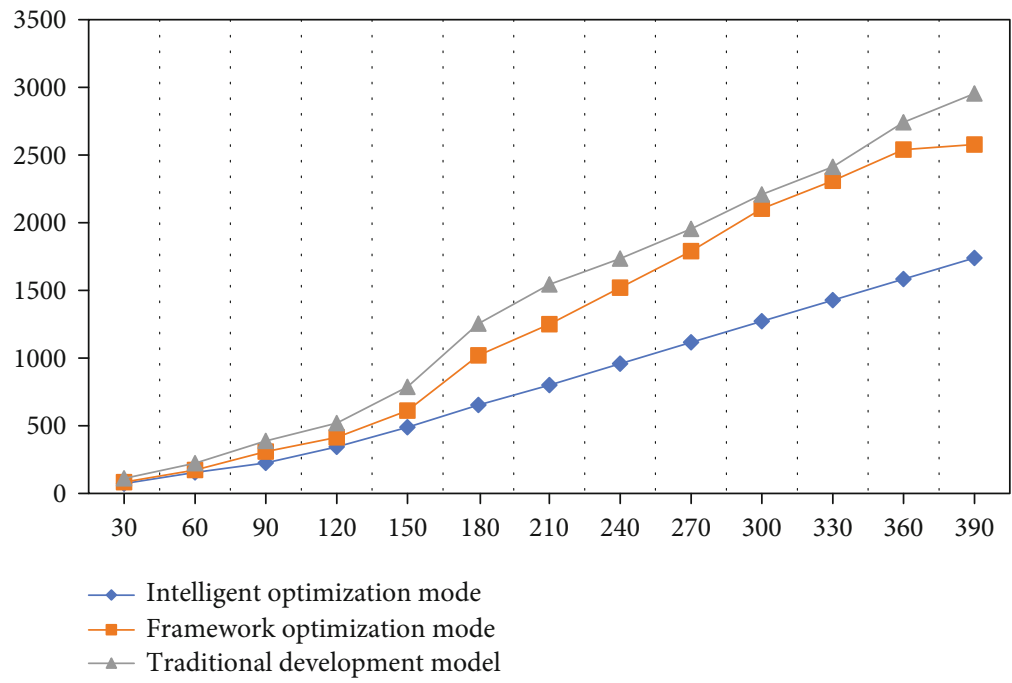

FIGURE 11: ART-concurrent completed transaction volume curve.

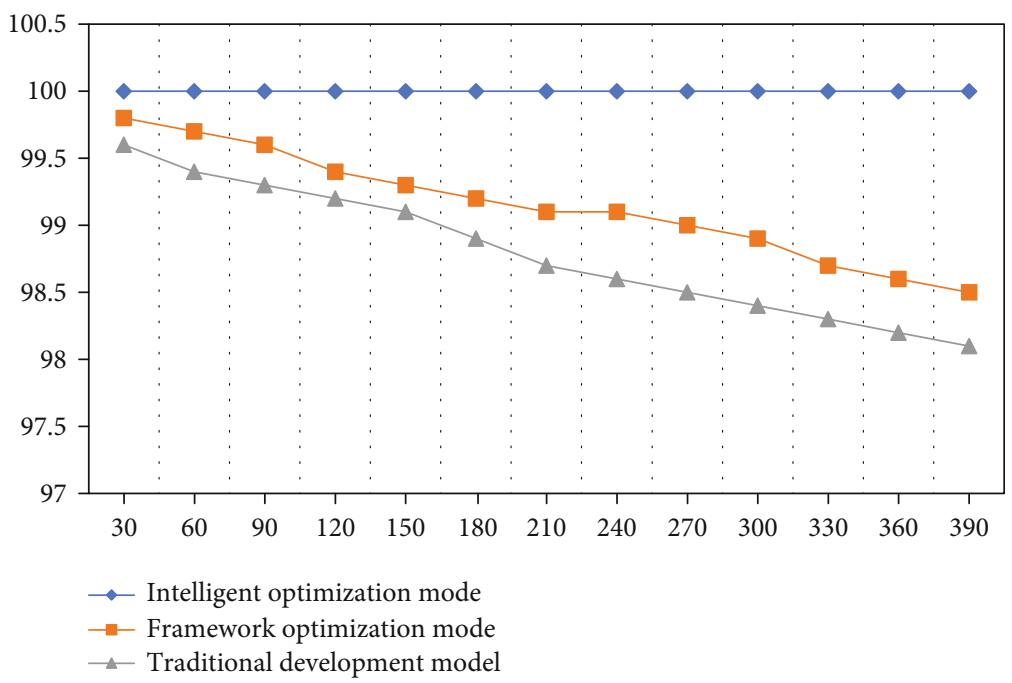

FIgURE 12: ART-concurrent business transaction success rate.

\subsection{System Performance Test}

3.4.1. System Specific Function Test. Detect with two indicators: the number of concurrent users and the response time. For the working status of a domestic hotel, the detection sys- tem draws a graph of response time and the number of users, and the result is shown in Figure 8.

3.5. Comparison of Specific Functions of the Block System. The system response time is tested, compared with other 
systems, and the test results are shown in Table 7 and Figures 9 and 10 .

Judging from the query time and success rate of concurrent information in Figures 9 and 10, the intelligent optimization system can have a very low average response time and the highest query success rate. The average response time will increase as the amount of concurrency increases, but the success rate shows a downward trend.

3.5.1. Business Transaction Processing Function Test. Test the business transaction processing function of the system. Compared with other system users, the test results are shown in Table 8 and Figures 11 and 12.

Judging from the response time and success rate of completing business transactions in Figures 11 and 12, the intelligent optimization system can have a very low average response time and the highest query success rate.

\section{Conclusion}

Speed up and strengthen the hotel's financial management business, establish a sound financial management system, reduce management expenses and costs, and increase the hotel's revenue to comply with the fierce market competition. In the operation and management of large-scale tourism enterprises in my country, managers must be good at discovering existing problems and actively explore and take effective measures to completely solve these problems. New corporate management concepts should be implemented in various management tasks. Our hotel is ready for future socioeconomic sustainability.

Under the condition of market economy, the challenges and pressures brought to the hotel industry are enormous. If you want to be in an invincible position in this fierce competition, you must strengthen the management in all aspects, keep learning, and keep exploring and innovating, and then, you can build a boutique hotel. Strengthen the cultivation of talents, and improve service quality: talent is the most precious resource of enterprises, which has become the consensus of people of insight. Hotel competition is the competition of talents, and talents are the root of hotel survival and development. With the advent of the globalization of Chinese economy, the goal of hotel service in China has gradually changed from nationalization to globalization, and the diversification of customers means the need for diversified professionals. Hotel enterprises need to be employee-centered on the premise of customer satisfaction, because service quality, customer satisfaction, and enterprise performance all depend on employees, and all services are delivered by employees. "There are no satisfied customers without satisfied employees" is the consensus of successful hotel managers. Recruiting and retaining talents are the most concerned issue in any industry.

\section{Data Availability}

The experimental data used to support the findings of this study are available from the corresponding author upon request.

\section{Conflicts of Interest}

The author declared that there are no conflicts of interest regarding this work.

\section{Acknowledgments}

This work was sponsored by Project of Department of Education of Zhejiang Province (Zhejiaohan[2021]47) and Project of Tourism College of Zhejiang (2019GCC13).

\section{References}

[1] L. I. Lin, "Innovation and development of financial management in modern hotel industry," Management \& Technology of SME, vol. 27, no. 1, pp. 6-6, 2019.

[2] Bagaeva Ksenia Olegovna source: Corporate Financial, Financial Management in the Hotel Business: Basic Approach and Foreign Experience Application, Корпоративныефинансы, 2011.

[3] T. C. Canada, "Tourism, that's your business. A programme of financial management for the Canadian hotel industry," Study Guide, vol. 52, no. 12, pp. 22-36, 1983.

[4] Q. Wang and B. Zhang, "Research and implementation of the customer-oriented modern hotel management system using fuzzy analytic hiererchical process (FAHP)," Journal of Intelligent and Fuzzy Systems, vol. 40, no. 4, pp. 8277-8285, 2021.

[5] A. Akincilar and M. Dagdeviren, "A hybrid multi-criteria decision making model to evaluate hotel websites," International Journal of Hospitality Management, vol. 36, pp. 263-271, 2014.

[6] W. Xiong and W. U. Yuanmei, "The influence of intelligence application on hotel performance in luxury hotels: a case study in the Pearl River Delta," Tourism Tribune, vol. 22, pp. 22-36, 2018.

[7] X. U. Chaohui, "Design of intelligent ordering system based on Android mobile phone," Machine Design and Manufacturing Engineering, vol. 25, no. 23, pp. 11-16, 2016.

[8] G. Tildikova, "The impact of sustainable growth indicators on hotel's financial management," Jyväskylän Ammattikorkeakoulu, vol. 2, no. 3, pp. 1-9, 2014.

[9] Y. Yang, A study of hotel management financial competencies with the focus on revenue and cost management, [Ph.D. thesis], Kent State University, 2014.

[10] C. Burgess, "The hotel financial manager - challenges for the future," International Journal of Contemporary Hospitality Management, vol. 12, no. 1, pp. 6-12, 2000.

[11] C. L. Burgess, "The hotel financial controller: a member of the management team," in Accounting and finance for the international hospitality industry, Butterworth-Heinemann, 1998.

[12] X. G. Ding, "Application of cash flow statement in hotel financial management," Journal of Shaanxi Normal University (Natural Science Edition), vol. 23, no. 2, pp. 55-75, 2001.

[13] K. L. Xie, K. So, and W. Wang, "Joint effects of management responses and online reviews on hotel financial performance: a data-analytics approach," International Journal of Hospitality Management, vol. 62, no. 62, pp. 101-110, 2017.

[14] S. Al-Shourah and A. A. Shourah, "An examination between total quality management and hotel financial performance: evidence from Jordanian international hotels," International Journal of Information and Decision Sciences, vol. 23, no. S1, pp. $418-431,2020$. 
[15] Y. Yang, "Effects of the size of acquisition on a hotel group's financial performance," Journal of Hospitality Financial Management, vol. 27, no. 1, pp. 6-6, 2019.

[16] Y. Li, "Analysis on how to promote the refined construction of hotel enterprise financial management," Manager, vol. 11, pp. 22-52, 2011.

[17] A. Banerjee, V. Mukherjee, and S. P. Ghoshal, "Seeker optimization algorithm for load-tracking performance of an autonomous power system," International Journal of Electrical Power \& Energy Systems, vol. 43, no. 1, pp. 1162-1170, 2012.

[18] K. Ikeda, T. M. Baduge, T. Umedu, H. Yamaguchi, and T. Higashino, "ALMware: a middleware for application layer multicast protocols," Computer Communications, vol. 34, no. 14, pp. 1673-1684, 2011.

[19] Z. Jia, "Problems and countermeasures in financial management of a star hotel in Shenzhen," Research on Communication Power, vol. 3, no. 6, pp. 185-187, 2019.

[20] Sun Microsystems Icn, Core J2EE Patterns2022, http://sun .com/blueprints/coreJ2EEpatterns/index.html.

[21] S. Mingxia, Research and application of component-based software reuse technology, [Ph.D. thesis], Wuhan University of Technology, 2009.

[22] H. Qinghua and Y. Liqing, "The research and application of Struts architecture in talent training system," Software Guide, vol. 12, pp. 22-36, 2010.

[23] G. Chen, X. Xie, and S. Li, "Research on complex classification algorithm of breast cancer chip based on SVM-RFE gene feature screening," Complexity, vol. 2020, Article ID 1342874, 12 pages, 2020.

[24] W. Ling, "Research on the financial management innovation of hotel enterprises under the new situation," China's Foreign Trade, vol. 16, pp. 22-36, 2011.

[25] C. Szyperski, D. Gruntz, and S. Murer, Component software: beyond object-oriented programming, Pearson Education, 2003. 